\title{
The Influence of LDPE Content on the Mechanical Properties of HDPE/LDPE Blends
}

\author{
Anour Shebani ${ }^{1}$, Abdalah Klash ${ }^{1}$, Rabea Elhabishi ${ }^{1}$, Shalh Abdsalam ${ }^{1}$, Hassan Elbreki ${ }^{2}$ and Wael Elhrari ${ }^{1 *}$ \\ ${ }^{1}$ Polymer Research Center, Libya \\ ${ }^{2}$ Industrial Research Center, Libya \\ *Corresponding author: Wael Elhrari, Polymer Research Center, Tripoli, Libya, Email: wael@prc.ly
}

Submission: 眥 March 23, 2018; Published: 眥 August 20, 2018

\begin{abstract}
Mechanical properties of blend of high density polyethylene (HDPE) and low density polyethylene (LDPE) have been investigated. Four different HDPE/LDPE blends with various ratio $\left(80 / 20,60 / 40,40 / 60\right.$, and 20/80) were prepared by melt-mixing technique using mini-twin-extruder at $200{ }^{\circ} \mathrm{C}$ and 90rpm. Characterization tests including tensile and impact strength tests as well as hardness have been performed in order to better understand the behavior of these blends. Information on ductility and toughness were obtained from the stress-strain curves of HDPE/LDPE blends. Mechanical properties were varied according to LDPE content. Blends-rich with LDPE showed to have lower strength and hardness and higher elongation, impact strength, ductility and toughness than blends-rich with HDPE. Blend with the composition (HDPE (40)/LDPE (60)) showed comparatively better overall mechanical properties.
\end{abstract}

Keywords: Blend; High and low density polyethylene; Tensile strength; Impact strength; Hardness

\section{Introduction}

Polymer blends have become more popular in research and in application because they offer a key option in solving emerging application requirements. Blending of chemically different polymers is an important tool in industrial production for tailoring products with optimized material properties [1]. Polymer blends offer a route for combining the favorable properties of different polymers to enhance various properties, which could not be obtained through the use of a single polymer. Polymer blends represent very important field in processing of new materials, which has better properties in comparison with the neat polymers. They are significant also from ecological and economical viewpoint $[2,3]$. There are five reasons to implement polymer blends; higher performance at a reasonable price, modification of performance as a market develops, extending the performance of expensive resins, reuse of plastics scrap and generation of a unique material as far as its process ability and/or performance are concerned [4]. Today the market pressure forces the resin manufacturers to provide better, more economic materials with superior combinations of properties, not as a replacement for wood or steel, but rather to replace the more traditional polymers [5]. Outstandingly, polymer blend technology could quickly respond to developing needs [6]. In other words, the properties of the blends could be manipulated according to their end use by correct selection of the component polymers [7].

A polymer blend is a member of a class of materials analogous to metal alloys, in which at least two polymers are blended together to create a new material with different properties. Their overall performance depends on the properties and composition of the individual components, the morphology of the blends and the interfacial properties between the blend components [8]. For example, the low interfacial adhesion between the polymeric components is responsible for a decrease in mechanical properties, including impact strength; strain at break and ductile to brittle transition [9]. A variety of polymer blends have been explored in recent years [10]. Generally, there are five main types of polymer blends: thermoplastic-thermoplastic blends; thermoplastic-rubber blends; thermoplastic-thermosetting blends; rubber-thermosetting blends; and polymer-filler blends. Thermoplastic-thermoplastic blends like polyethylene (PE) blends have been a topic of great academic and commercial interest for the past decades, owing to its relevancy to the understanding of processing and performance properties of blends containing different types of polyethylenes (PEs) [11]. PE-PE blends include low density PE/linear low density PE (LDPE/LLDPE), high density PE/low density PE (HPDE/LDPE), linear low density PE/high density PE (LLDPE/HDPE) and low density PE/linear low density PE/high density PE (LDPE/LLDPE/ HDPE). Blending was reported to improve process ability and mechanical properties of the neat PEs; HDPE, LDPE and LLDPE [2]. Blending of PEs has become a common industrial practice [12].

PEs could be classified according to their density which is a result of their degree of crystallinity and type and content of branches. Three types of PEs are commonly accessible: HDPE, LDPE, and LLDPE. These polymers have the same chemical 
formulas but differ in the density of their molecular chains due to the manner they are formed [13]. HDPE has linear structure with very few or no branching and possesses high degree of crystallinity. On the other hand, LDPE has chaotic structure with short and long chain branches and lower degree of crystallinity in comparison to HDPE. Although, there exists a basic disagreement over the issue of miscibility of HDPE with LLDPE or LDPE, it was agreed that branch content of branched component was the major molecular factor that controls miscibility of HDPE/LLDPE and HDPE/LDPE blends [14]. However, the most important parameter, governing PEs properties, is density which is taken as a measure of short chain branches. As crystallinity decreases with decreasing bulk density, the product becomes softer and more pliable, clarity and toughness increase while yield strength decreases [15].

A number of researches on PE blends have been published [1622]. PE blends could be miscible, partially miscible or immiscible depending on molecular parameters such as: molecular weight, molecular weight distribution, Branch content and distribution and composition distribution [23-28]. However, it could be noted that blending different PEs generally causes improvement in overall mechanical properties and durability if the correct selection and composition are achieved. Accordingly, it is interesting to explore the properties of blends of these materials. In this work, the influence of LDPE content on the mechanical properties of HDPE/ LDPE blends was studied.

\section{Experimental}

\section{Materials}

The polymers used in this study are commercial grades; LDPE from Lyondel Basell (PE 1840H) and HDPE from Ras Lanuf Co. (Libya) (HDF-5116). The melt flow index (MFI) and density values of LDPE are $1.5 \mathrm{~g} / 10 \mathrm{~min}$ (ASTM D 1238, $190^{\circ} \mathrm{C}, 2.16 \mathrm{~kg}$ ) and $919 \mathrm{~g} / \mathrm{cm}^{3}$ (ASTM D 1505, $23{ }^{\circ} \mathrm{C}$ ), respectively. LDPE (PE 1840H) can be used for blow-fill-seal applications such as bottles, vials and healthcare applications like caps, closures, collapsible tubes, medical devices and medical films. Whereas the melt flow index (MFI) and density values of HDPE are $0.15 \mathrm{~g} / 10 \mathrm{~min}$ (ASTM D1238, $190^{\circ} \mathrm{C}, 2.16 \mathrm{~kg}$ ) and $951 \mathrm{~g} / \mathrm{cm}^{3}$ (ASTM D $1505,23^{\circ} \mathrm{C}$ ), respectively. This type of material is suitable for general purpose of film applications such as bags, liners, barrier film, agriculture mulching film and co-extrusion film.

\section{Preparation of blends}

Table 1: Blends composition and codes.

\begin{tabular}{|c|c|c|}
\hline Sample & HDPE, $\%$ & LDPE, $\%$ \\
\hline HDPE & 100 & 0 \\
\hline Blend 1 & 80 & 20 \\
\hline Blend 2 & 60 & 40 \\
\hline Blend 3 & 40 & 60 \\
\hline Blend 4 & 20 & 80 \\
\hline LDPE & 0 & 100 \\
\hline
\end{tabular}

LDPE/HDPE blends with varying ratio (80/20, 60/40, 40/60, and $20 / 80$ ), were prepared by melt-mixing technique using minitwin-extruder (Haake mini CTW twin screw with average screw speed of (90rpm.), and the barrel temperatures set on $200{ }^{\circ} \mathrm{C}$. The specimens for mechanical properties were prepared using miniinjection mould (Xplore $12 \mathrm{ml}$ ) at $230{ }^{\circ} \mathrm{C}$. Details of the blends and codes are reported in Table 1.

\section{Determination of mechanical properties}

The tensile strength and elongation at break was determined using SATRA tensile tester. Tensile test were performed at room temperature. Four specimens $(73 \mathrm{~mm}-4 \mathrm{~mm}-2 \mathrm{~mm})$ were tested for each sample under speed test $(100 \mathrm{~mm} / \mathrm{min})$. Information on ductility and toughness were obtained from the obtained stressstrain curves. The charpy impact test was carried out to determine the impact strength of the HDPE, LDPE and all blend materials using (CEAST Resil Impactor tester), with impact energy of 15J. The specimens for impact test were prepared and notched according to ISO 179. Five specimens were tested for HDPE, LDPE and each blend.

The hardness of molded HDPE, LDPE and their blends were determined using a Shore D durometer (RayRan) in accordance with ISO 868:2003. Hardness value for each sample is an average of 8 measurements.

\section{Differential scanning calorimetry (DSC)}

The measurement of melting point was carried out with Netzsch DSC 204 F1 Phoenix. The samples of $5 \mathrm{mg}$ were encapsulated in aluminum pans, an empty aluminum pan was used as reference. Melting point of polymer blends was determined at heating rate of $10^{\circ} \mathrm{C} / \mathrm{min}$.

\section{Results and Discussion \\ Mechanical properties}

Mechanical properties are very helpful in describing the behavior of polymers under certain circumstances involve its behavior under stress. It provides reliable information that could help polymer scientists and engineers to find suitable application to such materials. For example, the choice of a PE for any particular application will generally involve a compromise between various properties. This is because, products made from PE are liable to be pulled, bent, twisted, impacted or mechanically deformed in some way during service.

Mechanical properties of tensile strength, elongation at break, impact strength and hardness were evaluated for the HDPE, LDPE and their blends, and summarized in Table 2. It is important to note that the standard deviations are given in parentheses next to the values of the mechanical properties.

\section{Stress-strain properties}

In the field of materials science, stress-strain curve is a widely used and practical tool that could help to understand and predict material behavior. It is possible to know many of a material's mechanical properties from its stress-strain curve. Mechanical properties such as tensile strength, elongation at break, ductility, and toughness could be derived from stress-strain curves. In addition, the stress-strain curves could also be used to obtain real 
information on the elastic and plastic deformation of a material during tensile test.

The results in Table 2 and Figure 1 revealed that the blends could bear a load of 14 to $16 \mathrm{MPa}$ with an increase in the elongation ranging from 214 to $315 \%$. It could also be noted that the blend 1 could withstand maximum load as compared to other blends. As shown in Table 2, HDPE has a higher tensile strength value than LDPE. The tensile properties are mainly dependent on the crystallinity of the polymer [29]. The polymer chains in HDPE are linear which they pack closer together, resulting in greater intermolecular forces and a more crystalline structure. In contrast, the molecular chains in the LDPE are more branched and farther apart from each other, which cause lower degree of crystallinity and lower bonding forces between chains, resulting lower strength.

Table 2: Mechanical properties of the HDPE, LDPE and their blends.

\begin{tabular}{|c|c|c|c|c|c|}
\hline Sample & $\begin{array}{c}\text { Tensile Strength, } \\
\text { (MPa) }\end{array}$ & $\begin{array}{c}\text { Elongation at Break, } \\
\mathbf{\%}\end{array}$ & $\begin{array}{c}\text { Impact Strength, (KJ/ } \\
\mathbf{m}^{\mathbf{2}} \mathbf{~}\end{array}$ & Hardness & Toughness (MPa) \\
\hline HDPE & $27.93(1.2)$ & $213.1(5.8)$ & $(35.7) 247.2$ & $91(0.6)$ & $1.89(0.3)$ \\
\hline Blend 1 & $16.37(0.8)$ & $214.3(3.7)$ & $(30.4) 461.1$ & $85(0.4)$ & $1.22(0.2)$ \\
\hline Blend 2 & $15.01(0.2)$ & $219.7(8.9)$ & $(55.2) 1314$ & $83.3(0.9)$ & $1.29(0.1)$ \\
\hline Blend 3 & $16.04(0.4)$ & $263.0(9.6)$ & $1421(40.7)$ & $81.9(0.9)$ & $1.92(0.7)$ \\
\hline Blend 4 & $14.09(0.9)$ & $314.5(2.9)$ & $(68.1) 1264$ & $80(0.0)$ & $2.47(0.1)$ \\
\hline LDPE & $9.93(0.3)$ & $349.0(9.6)$ & $(82.1) 1134$ & $72(1.9)$ & $6.06(0.7)$ \\
\hline
\end{tabular}

The tensile strength values of all the blends were in between values of neat polymers, as illustrated in Table 2 . A significant reduction in tensile strength is observed with increase in the LDPE content. This could be due to the reduction in crystallinity which takes place with addition of LDPE. Similar findings were reported in several studies [30,31]. Also, the reduction in crystallite size may be responsible of this behavior. According to many studies [32,33], the addition of LDPE could cause reduction in the crystallite size of both homopolymers in the HDPE/LDPE blends. Elongation at break values for HDPE, LDPE and their blends are presented also in Table 2. Elongation at break is the strain at which a polymer breaks when tested in tension at a controlled temperature. It is expressed in terms of the percentage of the original length. Elongation at break results showed that all the blends were deformed just like many plastics do. LDPE has very high elongation before breaking in comparison to HDPE. This could be attributed to the difference in the crystallinity between the two polymers, as discussed previously. This indicates that the rate of deformation, however, varies according to LDPE content, i.e. the higher the LDPE content, the higher the deformation rate.

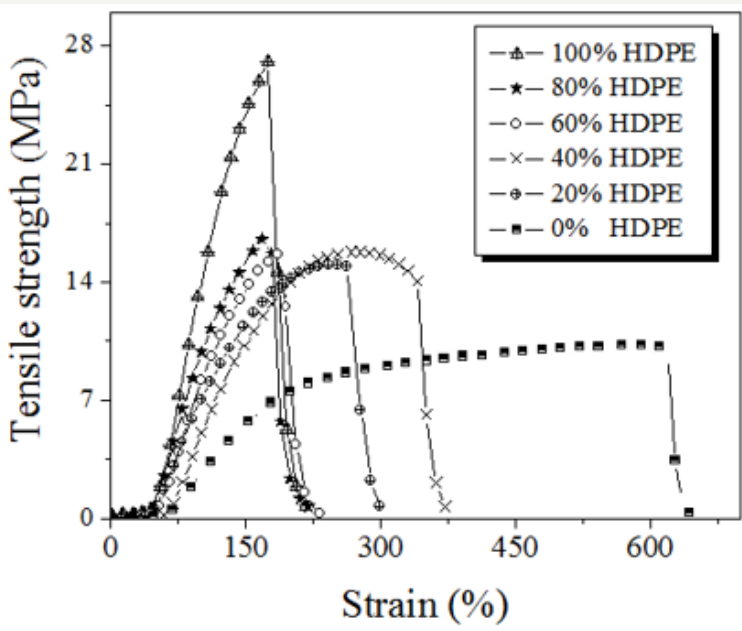

Figure 1: Stress-strain curves of the HDPE, LDPE and their blends.
The typical stress-strain curves for HDPE, LDPE and their blends are shown in Figure 1. The hardest material is HDPE, while the softest materials are LDPE. This is expected since LDPE is softer and has low tensile strength compared to HDPE because it has lower crystallinity content [34], as explained above. Since many papers [34-39] are available in the literature studying the stress-strain relationship of different grades of PEs, the stressstrain relationship of HDPE and LDPE are omitted in the following discussion.

The stress-strain curves show that the behavior of all types of blends which are intermediate between their parent polymers, HDPE and LDPE. As with all polymer blends, the final blend properties depend on the properties of the individual materials and the blend composition [40]. Variation in composition may affect the crystallinity and phase morphology of HDPE/LDPE blends. According to Nora \& Eguiazábal [41], in blends of two crystallizable polymers, the physical properties may be altered not only by the blend composition and the phase morphology, but also by the crystallization behavior of each of the two components.

As shown in the Figure 1, the stress-strain curves for the all blends could be divided into two main distinct deformation regions, which are the elastic deformation and the plastic deformation. In the elastic region stress is linearly proportional to strain and the deformation is reversible. The elastic deformation is temporary and is fully recovered when the stress is removed. As seen in Figure 1 , the elastic region in the stress-strain curves of all blends seems to be very small. According to Bijin [42], the elastic region is very small and the mechanical properties in small deformations (elastic region) are generally influenced by crystallinity, and the thickness of the crystallite lamellae. On the other hand, the plastic region stress is apparently opposite the elastic region stress. The plastic deformation is permanent and is not recovered when the stress is removed. Redakcji et al. [43] reviewed many studies and stated that plastic deformation of a semi-crystalline polymer is a complex process, because different elements of amorphous and crystalline phases participate in it, depending on the level of deformation. 
The mechanical coupling between the amorphous phase and the crystalline phase is crucial for the plastic deformation [42]. Locker et al. [44] found from the simulation results that the plastic deformation mechanism depends on the concentration of molecules that link adjacent crystallites, including tie chains and bridging entanglements.

The elongation or deformation during tensile testing could provide a relative indication of the ductility of the polymers being evaluated [45]. Ductility is the ability of materials to undergo plastic deformation before break, which normally expressed as percent elongation or percent area reduction from a tensile test. Materials with relatively high levels of elongation are indicative of highly ductile performance. According to this, the ductility of the HDPE/ LDPE blends seems to increase as the LDPE content increases. Blends 3 and 4 exhibit the more ductile failure characteristics in comparison to other blends. The mode of failure is either brittle or ductile, depending on the blend composition [46]. It is important to note here that the plastic deformation that occurs during ductile failure could be useful as warning sign to the failure that may occur in later stages. For this reason, high ductile materials are expected to have good workability. Consequently, ductile failure is preferred in most polymer applications.

Other properties like toughness could be obtained from the stress-strain curve. Toughness could be determined from the area under the stress-strain curve. Toughness is the ability of a material to absorb energy and plastically deform without failure. It is different from ductility, although they are often related. Basically, toughness is used to describe the combination of strength and ductility. As might be expected, as the LDPE content increases, there is usually an increase in toughness, as illustrated in Figure 2. The combination of strength and ductility (ductility here was expressed as percent elongation) for all the blends are shown in Figure 2 . Blend 3 exhibits the best combination of strength and ductility, which resulted higher toughness in comparison to other blends. On the other hand, lower combination of strength and ductility (or toughness) was exhibited by blend 1 and blend 4, respectively. Toughness results for all HDPE/LDPE blends were calculated and summarized in Table 2 .

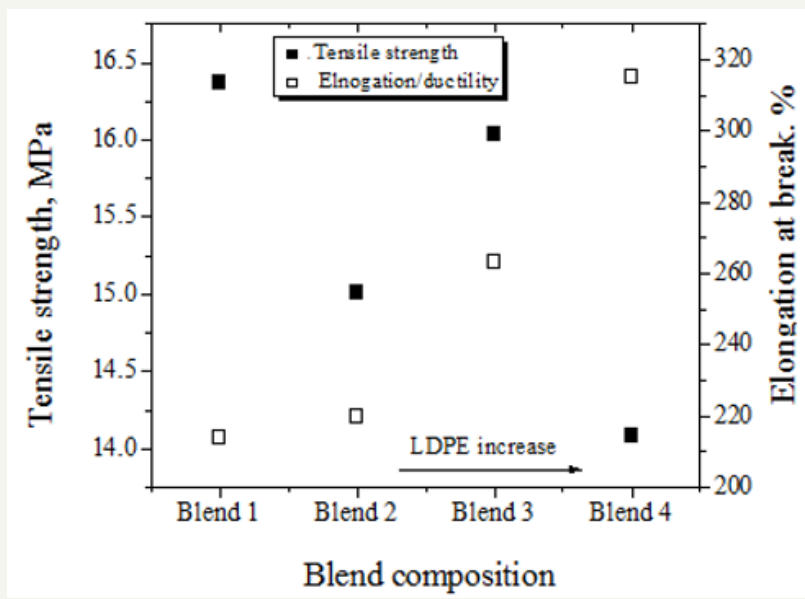

Figure 2: Combination of strength and elongation versus blend composition.

\section{Impact strength properties}

As seen in Figure 3, the impact strength is found to increase with increasing the LDPE content. Blend 3 has the highest impact strength value $\left(1421 \mathrm{KJ} / \mathrm{m}^{2}\right)$. This indicates that addition $60 \% \mathrm{LDPE}$ content increased the impact strength value to approximately 17 and $80 \%$ compared to neat LDPE $\left(1134 \mathrm{KJ} / \mathrm{m}^{2}\right)$ and HDPE $(247 \mathrm{KJ} /$ $\mathrm{m}^{2}$ ), respectively. Even in the cases of blends 2 and 4, the impact strength values (1314 and $1264 \mathrm{KJ} / \mathrm{m}^{2}$, respectively) were higher than that of neat polymers. On the other hand, the lowest impact strength value was obtained for blend $1\left(461.16 \mathrm{KJ} / \mathrm{m}^{2}\right)$. The later impact strength value was higher than that of HDPE and lower than that of LDPE. These results are in good agreement with toughness results.

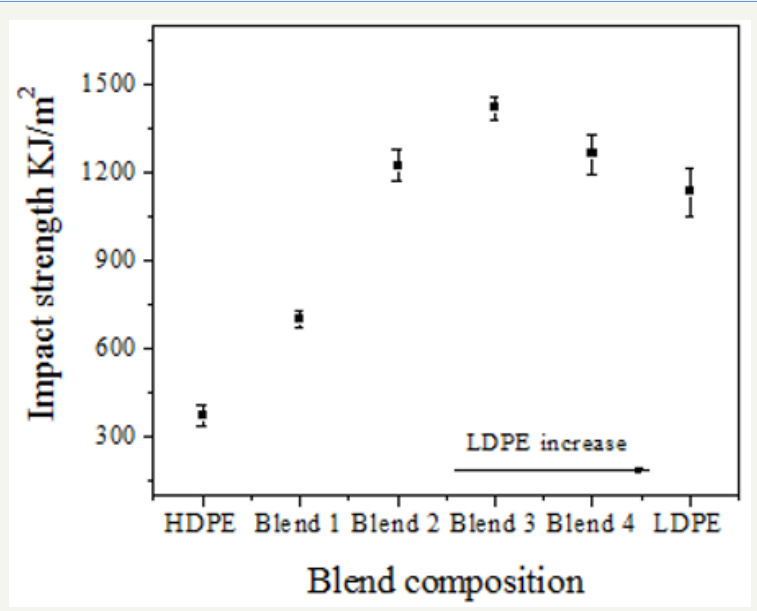

Figure 3: Impact properties of HDPE, LDPE and their blends.

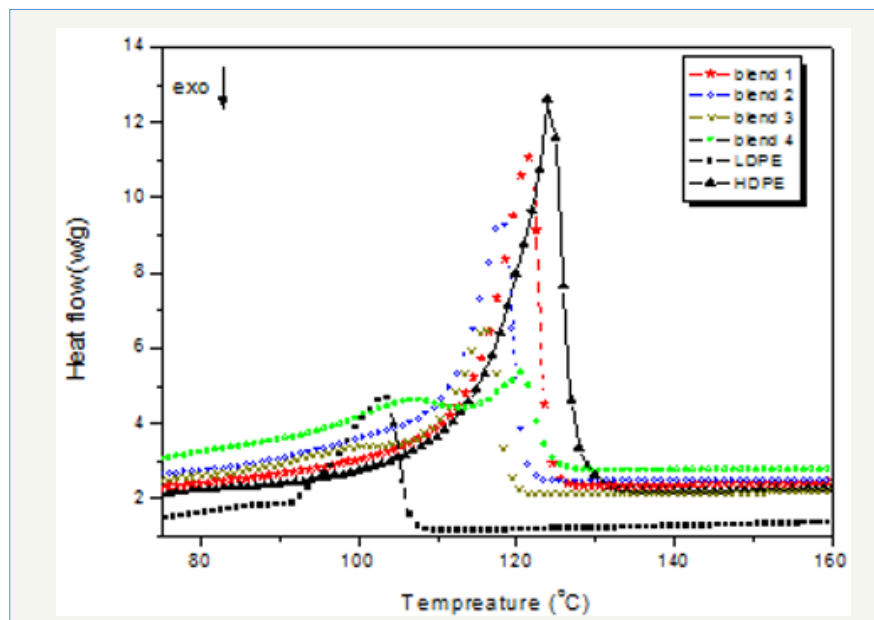

Figure 4: DSC heating curves of HDPE, LDPE and their blends.

It is important to note here that the impact strength of blends 2 , 3 and 4 have higher impact strength compared to LDPE. This could be attributing to the reduction in crystallites size. It is assumed that the branches in LDPE act as barriers to HDPE chains, which hinders the crystallization of the HDPE chains further, this lead to an increase the strain on the crystal, decreasing the thickness and lowering the melting temperature. As shown in Figure 4, there is a noticeable shift of both the HDPE and LDPE peaks towards one 
another, indicating some interaction on the molecular level. The lamellae that comprise the crystalline phase decrease in population and thickness as the LDPE content increases. The formation of smaller crystals in most blends seems to present a better capability for absorbing energy before braking and subsequently increasing the impact properties in comparison to homopolymers.

\section{Hardness properties}

Hardness is an important parameter in many industrial applications of polymer and is sometimes a key requirement. For examples, surfaces hardness is an important mechanical characteristic of polymer used in replacement of joints in the body [47]. Hardness is defined as the resistance of a material to deformation, particularly permanent deformation, indentation, or scratching. From Table 1 and Figure 5, it can be noticed that the highest hardness value was recorded for the HDPE, while the lowest hardness value was attained by the LDPE. Indeed, HDPE has a greater hardness and tensile strength than LDPE. This is because HDPE is more rigid than LDPE due to the higher crystallinity content, as discussed previously. Crystallinity has a direct influence on tensile strength and hardness [48]. It was evident that hardness properties was decreased as the LDPE content increased which result in an increase in the blend surface resistance to the indentation.

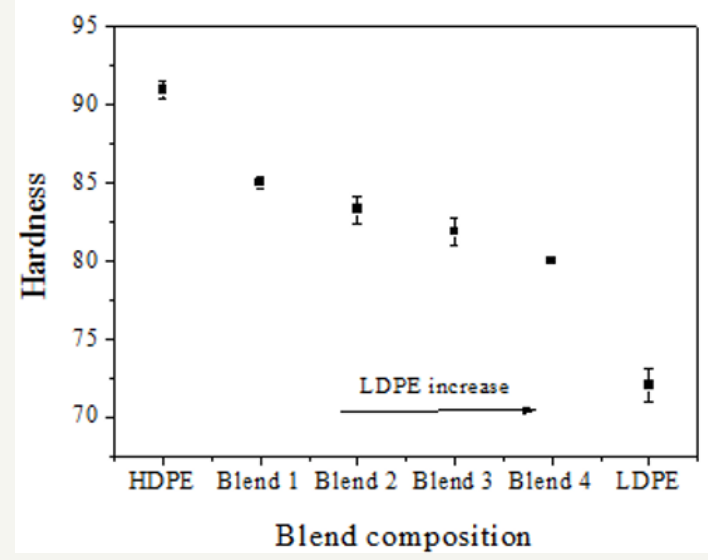

Figure 5: Hardness of the HDPE, LDPE and their blends

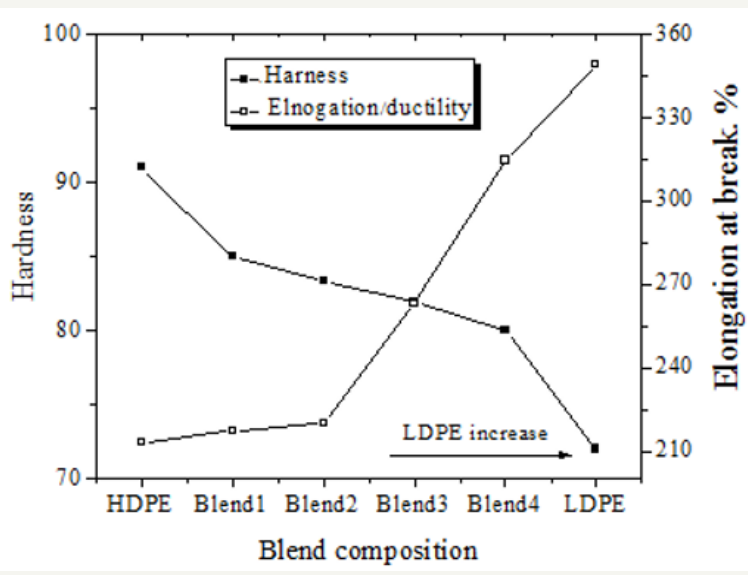

Figure 6: Hardness versus ductility for HDPE, LDPE and their blends.
These findings are in excellent agreement with the above mechanical results. As mentioned in the literature [49], hardness varies inversely with ductility and the deformations caused by a hardness indenter are of similar magnitude to those occurring at the ultimate tensile strength in a tensile strength test. This is because tensile strength and hardness are indicators of a material's resistance to plastic deformation, so they are roughly proportional. Figures $6 \& 7$ shows that the hardness results obtained in this study are in consistent with the theoretical perspectives present in the literature [50].

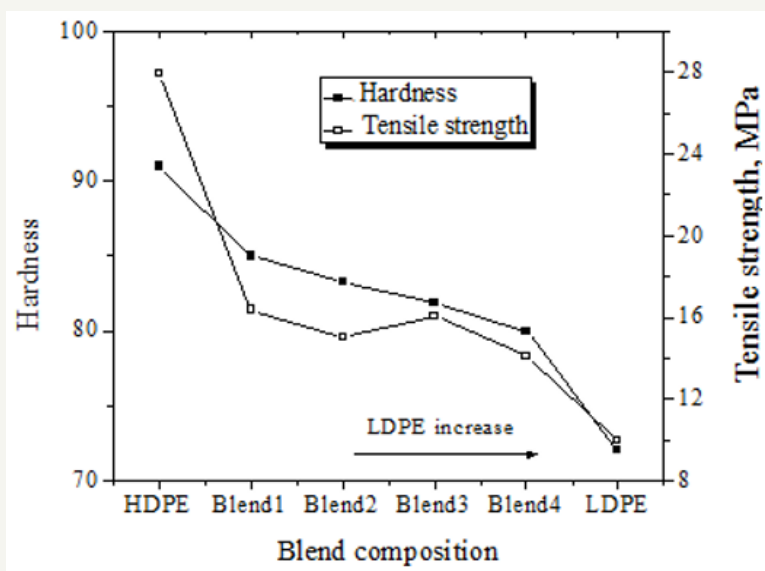

Figure 7: Hardness versus tensile strength for HDPE, LDPE and their blends.

It could be concluded here that increasing the content of LDPE in the HDPE/LDPE blends from $20 \%$ to $80 \%$ were caused a dramatic change in the behavior of these blends in comparison to the neat polymers and result different blends with different mechanical properties. Mechanical properties were varied according to the LDPE content. Blends-rich with LDPE (contain 80\% and 60\% LDPE) showed to have lower strength and hardness and higher elongation, impact strength, ductility and toughness than blends-rich with HDPE (contain $80 \%$ and $60 \%$ HDPE). Furthermore, blend with the composition (HDPE (40\%)/LDPE (60\%)) showed comparatively better overall mechanical properties than the neat polymers and other blends. However, polymer blend performance depends on certain factors: properties of polymer components, their content, morphology and the interaction between the polymer components in the blend. In the case of PE-PE blend, degree of crystallinity and crystallite size are the governing factors since the polymer components have the same chemical formulas.

\section{Conclusion}

LDPE/HDPE blends, with various ratio (80/20, 60/40, 40/60, and 20/80), were prepared by melt-mixing technique using minitwin-extruder. Characterization tests including tensile and impact strength tests as well as hardness have been performed. The following conclusions are made:

1. Mechanical properties of all blends were varied according to LDPE content.

2. Blends-rich with LDPE (contain $80 \%$ and $60 \%$ LDPE) showed to have lower strength and hardness and higher 
elongation, impact strength, ductility and toughness than blends-rich with HDPE (contain 80\% and 60\% HDPE).

3. Blend with the composition (HDPE (40\%)/LDPE (60\%)) showed comparatively better overall mechanical properties than the neat polymers and other blends.

4. Increasing the content of LDPE in the HDPE/LDPE blend from $20 \%$ to $80 \%$ were caused a dramatic change in the behavior of these blends in comparison to the neat polymers and result different blends with different mechanical properties.

\section{Acknowledgment}

The authors would like to thank Industrial Research Center who performed the tensile strength test.

\section{References}

1. Sihama ES, Abdullkhaliq FH, Alyaa HA (2013) Comparison of the characteristics of LDPE: PP and HDPE: PP Polymer Blends. Modern Applied Science 7(3): 33-42.

2. Utracki LA (1998) Commercial polymer blends. Chapter 3, Chapman \& Hall, London, UK.

3. Rachida K, Ismahane D (2011) Some mechanical and thermal properties of pc/abs blends. Materials Sciences and Applications 2: 404-410.

4. Utracki LA (1982) Economics of polymer blends. Polymer Engineering and Science 22(17): 1166-1175.

5. Lloyd MR (2007) Polymer blends: A comprehensive review. Hanser Gardner Publication, USA.

6. Leszek AU, Charles AW (2003) Polymer blends handbook. ( $\left.2^{\text {nd }} e d n\right)$, Springer, UK.

7. Paul DR (1989) Control of phase structure in polymer blends. Functional Polymers. In: Bergbreiter DE, Martin CR (Eds.), Plenum Press, New York, USA, pp. 1-18.

8. Strapasson R, Amic SC, Pereira MFR, Sydenstricker THD (2005) Tensile and impact behavior of polypropylene/low density polyethylene blends. Polymer Testing 24: 468-473.

9. Avraam I, Sanjay P (2011) Encyclopedia of polymer blends. Processing John Wiley and Son, Germany, 2: 1-528.

10. Hafiz AM, Hilmi M, Murugesan T, Nasir R, Mohshim DF, et al. (2013) Recent applications of polymer blends in gas separation membranes. Chemical Engineering and Technology 36(11): 1838-1846.

11. Nabeela AM (2009) Studing the mechanical properties and morphology of ternary blends of polyethylene. Eng and Tech Journal 27(6): 11971202.

12. Tayyab H, Ibnelwaleed AH (2004) Effect of short chain branching of LDPE on its miscibility with linear HDPE. Macromolecular Materia Engineering 289(2): 198-203.

13. Ibitoye SA, Adeleke AA, Aramide FO, Olawale JO, Tiamiyu AO, et al. (2013) Some Mechanical properties of SiC-treated recycled HDPE. International Journal of Materials and Chemistry 3(3): 45-50.

14. Ibnelwaleed AH, Tayyab H, Basel FAS, Khaled M (2003) Miscibility of hexene-LLDPE and LDPE blends: influence of branch content and composition distribution. Polymer 44(16): 4665-4672.

15. Abdoul AAS (2010) Characterization, optimization and modelling of PE blends for pipe applications. A Doctoral Thesis, Loughborough University, UK

16. Paul DR (1980) Polymer blends 1 \& 2. In: Newman S (Ed.), Academic Press, New York, USA.
17. Richard SS (1991) Some scattering studies of polymer microstructures, surfaces, and interfaces. Pure and App Chem 63(7): 941-950.

18. Shi RH, Thein K, RICHARD SS (1987) Characterization and properties of polyethylene blends I: Linear low-density polyethylene with highdensity polyethylene. Journal of Polymer Science: Part B: Polymer Physics 25(1): 71-87.

19. Kyucheol C, Byung HL, Kyu MH, Hoseok L, Soonja C (1998) Rheological and mechanical properties in polyethylene blends. Polymer Engineering and Science 38(12): 1969-1975.

20. Fadhel BCL, Jean LH (2001) Long period analysis in blends of highdensity and low density polyethylene. e-Polymers 1(1): 20.

21. Miller P, Igor S, Iovenitti P, Masood S (2001) Rheological properties of blends of recycled HDPE and virgin polyolefins. Polymer Recycling 6(4): 181-186.

22. Rana SK (2002) Blend of high-density polyethylene and a linear low-density polyethylene with compositional-invariant mechanical properties. Journal of Applied Polymer Science 83(12): 2604-2608.

23. Cho K, Lee BH, Hwang KM, Lee S, Choe S (1989) Polym Eng Sci 29: 1969.

24. Martinez SJ, Cuesta MS, Plans J (1991) On phase separation in high- and low-density polyethylene blends: 1 . Melting-point depression analysis. Polymer 32(16): 2984-2988.

25. Plans J, Cuesta S, Martinez-SJ (1991) On phase separation in high- and low-density polyethylene blends: 2. A working model. Polymer 32(16): 2989-2991.

26. Xu J, Xu X, Chen L, Feng L, Chen W (2001) Effect of composition distribution on miscibility and co-crystallization phenomena in the blends of low density polyethylene with conventional and metallocenebased ethylene-butene copolymers. Polymer 42(8): 3867-3874.

27. Liu C, Wang J, He J (2002) Rheological and thermal properties of m-LLDPE blends with m-HDPE and LDPE. Polymer 43(13): 3811-3818.

28. Fan ZJ, Williams MC, Choi P (2002) A molecular dynamics study of the effects of branching characteristics of LDPE on its miscibility with HDPE. Polymer 43(4): 1497-1502.

29. Vijayakumar PC, Jeevan KR, Anish J, Ekwipoo K, Jobish J (2014) Mechanical properties and morphology of ER/PS blends. Journal of Material Sciences 2(2): 9-16.

30. Gautam S, Amarnath B, Pinaki B (2007) Rheological and mechanical properties of LDPE/HDPE blends. Journal Polymer-Plastics Technology and Engineering 45(6): 713-718.

31. Minick J, Moet A, Baer E (1995) Morphology of HDPE/LDPE blends with different thermal histories. Polymer 36(10): 1923-1932.

32. Decai CY, Jean MB, Edwin LT (1988) Highly oriented single-phase blend films of high- and low-density polyethylene. Journal of Materials Science 23(7): 2546-2552.

33. Noorunnisa KP, Mariam AM (2015) Processing and characterization of polyethylene-based composites. Journal of Advanced Manufacturing: Polymer and Composites Science 1(2): 63-79.

34. Robertson RE, Paul DR (1973) Stress-strain behavior of polyolefin blends. Applied Polymer 17(8): 2579-2595

35. Masayoshi K, Tomohiko M (1988) Stress-strain curve in polyethylene. Journal of the Society of Material Science 37(423): 1391-1396.

36. Patlazhan SA, Hizoum K, Rémond Y (2008) Stress-strain behavior of high-density polyethylene below the yield point: Effect of unloading rate. Polymer Science Ser A 50(5): 789-796.

37. Kwon HJ, Jar PYB (2008) On the application of FEM to deformation of high-density polyethylene. International Journal of Solids and Structures 45(11-12): 3521-3543 
38. Jennifer LJ, Daniel TC, Jermaine MB, Ajmer KD, Eric NB, et al. (2016) Mechanical properties of low density polyethylene. Journal of dynamic behavior of Materials 2(54): 411-420.

39. Norbert R, Manfred S, Rick F, Chul BP, Jin W (2003) PP-blends with tailored foamability and mechanical properties. Cellular Polymers 22(5): 315-327.

40. Nora A, José IE (2015) Improved mechanical properties of compatibilized polypropylene/polyamide-12 blends. International Journal of Polymer Science 2015: 1-8.

41. Bijin X (2014) Contribution to the study of elastic and plastic deformation mechanisms of polyethylene and polypropylene as a function of microstructure and temperature. PhD Thesis, National Institute of Applied Sciences of Lyon (ANSA), Lyon, France.

42. Locker CR, Kim JM, Rutledge GC, Tsou AH (2018) Molecular-level plastic deformation of polyethylene and its dependence on amorphous topology. The World Innovation Conference, Washington DC, USA.

43. Od R, AndrzeJ P, Ga£êski A (2011) Cavitation during tensile drawing of semi crystalline polymers. Polimery 56(9): 625-706.
44. Awwa Manual M55 (2006) PE pipe design and installation. American Water Works Association.

45. George PS, Gabriel OS (1999) Polymer blends and alloys. Marcel Dekker Inc, USA.

46. Marcela B, Alexey K (2015) Ion beam treatment of polymers: application aspects from medicine to space. ( $\left.2^{\text {nd }} e d n\right)$, Elsevier Ltd, USA.

47. Robert CW (2009) Minimally processed refrigerated fruits \& vegetables. In: Kit LY (Ed.), The Wiley Encyclopedia of Packaging Technology. ( $3^{\text {rd }}$ edn), Wiley \& Sons Inc, USA.

48. Norman ED (2013) Mechanical behavior of materials. (4 ${ }^{\text {th }}$ edn), Pearson Education Limited, USA.

49. Bharal B (1999) Prinicple and application of tripolgy. John Wiley \& Sons, USA.

50. Stephen RB, George Z, Xiaoming C (2017) Solid-state properties of pharmaceutical materials. John Wiley \& Sons, USA.
Creative Commons Attribution 4.0 International License

For possible submissions Click Here

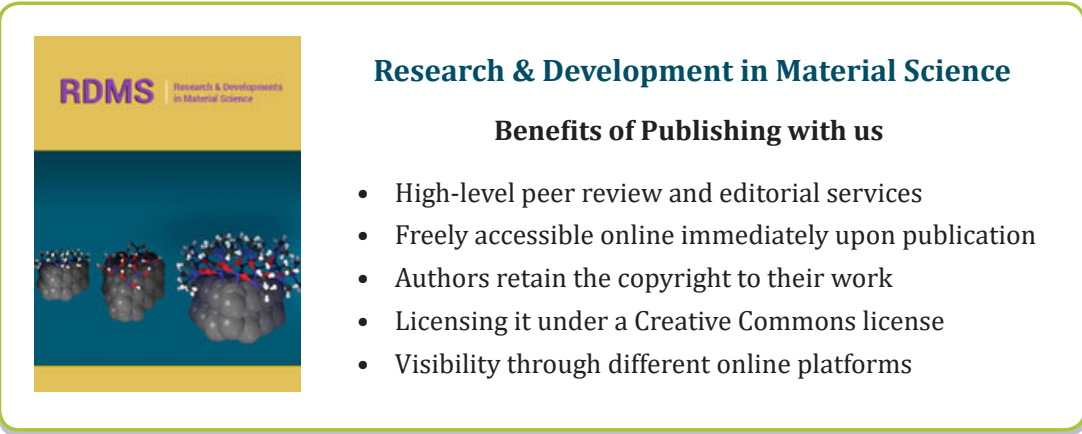

